\title{
Use of fluorescent in situ hybridisation for the visualisation of Helicobacter pylori in real drinking water biofilms
}

\author{
S.M. Bragança*, N.F. Azevedo***, L.C. Simões*, C.W. Keevil ${ }^{* \star}$ and M.J. Vieira* \\ ${ }^{*}$ Centro de Engenharia Biológica, Universidade do Minho, 4700-057 Braga, Portugal \\ (E-mail: sofiabraganca@gmail.com; nunoazevedo@deb.uminho.pt; luciachaves@deb.uminho.pt; \\ mjv@deb.uminho.pt) \\ **Environmental Healthcare Unit, School of Biological Sciences, University of Southampton, UK \\ (E-mail: C.W.Keevil@soton.ac.uk)
}

\begin{abstract}
A fluorescently labelled peptide nucleic acid (PNA) probe has been applied for the in situ detection of Helicobacter pylori in drinking water biofilms. The method was originally applied to real pipe samples removed from a drinking water distribution system (DWDS) but the curvature and the heavy fouling of the pipes prevented an accurate detection of the bacterium by epifluorescence microscopy. Therefore, two semi-circular flow cells were placed in a bypass of the DWDS, and coupons with up to 72 days of exposure were regularly sampled and analysed for the presence of $H$. pylori. In the flat surfaces of the coupons, it was possible to sparsely detect cells exhibiting similar morphology to $H$. pylori that were emitting the PNA probe fluorescent signal. Coupons were also visualised under the microscope before the hybridisation procedure to serve as negative controls and ensure the validity of the method. This work corroborates the findings already published elsewhere that this bacterium might be present in DWDS biofilms. The method requires, however, highly trained personnel for an accurate detection of the pathogen and will need simplification before being routinely used in standard water analysis laboratories.

Keywords Biofilms; drinking water; Helicobacter pylori; peptide nucleic acids; rapid detection methods
\end{abstract}

\section{Introduction}

Helicobacter pylori is a Gram-negative, microaerophilic, pleomorphic bacterium known to inhabit the human gastrointestinal tract. Although most people harbouring H. pylori are asymptomatic, the bacterium has been implicated in the development of certain diseases, such as gastric ulcers and stomach cancers (Blaser and Atherton, 2004). There is still a lack of consensus on the way this bacterium is transmitted (Axon, 2006), but biofilms in drinking water are suspected to create a safe haven for the subsistence of the bacterium and hence promote a waterborne route of infection (Azevedo et al., 2006; Bellack et al., 2006).

Molecular methods, mainly based on PCR, were able to detect the presence of the bacterium in water and water-associated biofilms from wells, rivers and water distribution networks (e.g. Park et al., 2001; Bunn et al., 2002; Benson et al., 2004; Watson et al., 2004). Using these methods does not prove, however, that the bacterium still retains its viability and infectious capability. The only two studies describing the recovery of H. pylori from water systems used either an immunomagnetic separation coupled with standard culture techniques in wastewater samples (Lu et al., 2002) or a culture enrichment/PCR method in a local groundwater source (Flanigan and Rodgers, 2003). The first study reports the detection in water unready for human consumption while in the second the authors failed to show evidence that they specifically recovered $H$. pylori. Furthermore, neither of the studies has been consistently reproduced so far. 
Coupling of fluorescence in situ hybridisation (FISH) with viability dyes or direct viable counts has been already used to indicate the presence and physiological status of very diverse bacteria (e.g. Baudart et al., 2005; Savichtcheva et al., 2005). Trying to achieve that goal, we have successfully developed in situ detection using peptide nucleic acid (PNA) FISH for the spatial resolution of $H$. pylori in biofilms in laboratory-grown experiments (Azevedo et al., 2003a, b). PNAs are a synthetic DNA analogue developed in the early 1990s that proved to be capable of forming PNA/DNA and PNA/RNA hybrids of complementary nucleic acid sequences (Nielsen et al., 1991). PNA possesses a neutrally charged polyamide backbone that makes FISH procedures more efficient and easier to perform (Stender et al., 2002; Lehtola et al., 2005), and has been already used to detect other bacteria in water (Prescott and Fricker, 1999; Lehtola et al., 2006).

In the present work, a PNA probe that has been shown specifically to detect H. pylori in laboratory-grown biofilms was tested both directly on pipes of a real drinking water distribution system (DWDS) and in coupons of two flow cells placed in a bypass of the DWDS.

\section{Methods}

Description of the DWDS and direct analysis of real pipe samples

The DWDS system supplies treated river and groundwater to a population of approximately 130,000 inhabitants of the northern region of Portugal. Whenever a leakage on the system occurred, a circular section of approximately $7 \mathrm{~cm}^{2}$ in diameter was drilled in the damaged pipe using a compact rotary hammer DW563 (DeWALT, Edinburgh, UK) (Figure 1). Materials of the pipes tested included high density polyethylene, polyvinyl chloride (PVC), cement and cast iron. Previous to use, the blade of the rotary hammer was disinfected with ethanol. The circular sections were then transported under refrigeration to the laboratory in sterile boxes filled with cotton soaked in a solution of $20 \%$ glycerol. After arrival, coupons were washed in $5 \mathrm{~mL}$ of sterile water to remove loosely attached microorganisms. The processing time of the coupons up to this step was kept at just under two hours.

\section{Installation and sampling of the flow cells}

As an alternative method to perform PNA FISH analyses, flow cells were installed in a small sub-network of the above-mentioned DWDS that supplied treated river water to a population of 1,500 inhabitants. In this sub-network, water was collected from the river bedrock after filtration through sand, filtered again through activated carbon filters and
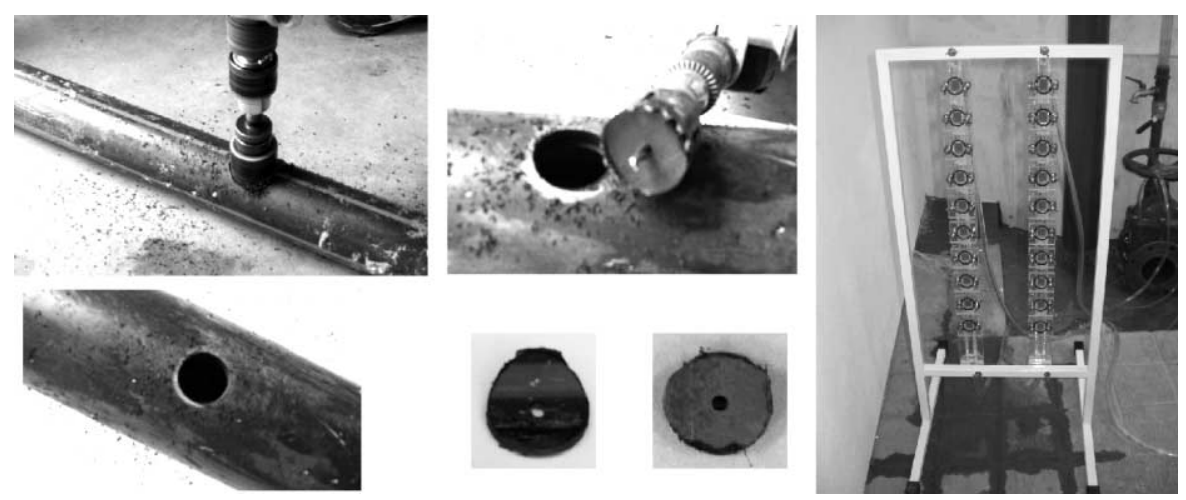

Figure 1 Different methods to obtain biofilms from a DWDS. On the left, a rotary hammer is used to drill two coupons out of pipes from a DWDS. On the right, two flow cells were installed in a bypass of a DWDS 
then treated with chlorine before $\mathrm{pH}$ adjustment with a solution of calcium hydroxide. Water was then pumped to a storage reservoir. The flow cells were connected in parallel to the distribution system using a $\frac{1}{2}$-inch PVC pipe at approximately $6 \mathrm{~km}$ downstream of the reservoir. This location corresponded to the end of the network, where chlorine concentrations were expected to be lower. The biofilm forming devices consisted of a semicircular Perspex duct with ten spaces on its flat surface where coupons of different materials can be inserted. In this case, both cells were equipped with PVC coupons of $2.4 \times 1.4 \mathrm{~cm}$. When sampling occurred, the transport of the coupons was performed in the same conditions as for the coupons from the DWDS pipes.

\section{Detection of $\boldsymbol{H}$. pylori in biofilms of DWDS using PNA FISH}

The PNA probe and the hybridisation procedure have been already tested and described elsewhere (Azevedo et al., 2003a). In short, coupons with biofilm attached were immersed in $90 \%$ ethanol during 10 minutes for fixation. The coupons were then covered with the hybridisation solution, which consisted of $10 \%$ (wt/vol) of dextran sulphate, $10 \mathrm{mM} \mathrm{NaCl}, 30 \%$ (vol/vol) formamide, $0.1 \%$ (wt/vol) sodium pyrophosphate, $0.2 \%$ (wt/vol) polyvinylpirrolidone, $0.2 \%$ (wt/vol) FICOLL, $5 \mathrm{mM}$ disodium EDTA, $0.1 \%$ (vol/vol) Triton X-100, $50 \mathrm{mM}$ of Tris $\mathrm{HCl}(\mathrm{pH} \mathrm{7.5)}$ and $200 \mathrm{nM}$ of the PNA probe (Oswell, Southampton, UK), for 90 minutes at $63^{\circ} \mathrm{C}$. The probe sequence was $5^{\prime}$-(TAATCAGCACTCTAGCAA)- $3^{\prime}$ and a fluorescent carboxyfluorescein molecule was connected in the $5^{\prime}$ terminal for microscopy detection. After hybridisation, coupons were washed at $63{ }^{\circ} \mathrm{C}$ for $30 \mathrm{~min}$ and visualised under epifluorescence microscopy. As a control experiment, each time the hybridisation procedure was performed one coupon was submitted to the same process, but with no PNA probe added during the hybridisation step. Coupons were then screened using a standard epifluorescence microscope (Carl Zeiss, Germany).

\section{Scanning electron microscopy}

Because free-living amoebae, which are typical predators found in biofilm ecosystems, were already found to provide conditions favouring the survival of $H$. pylori, it was attempted to detect the presence of protozoa in biofilm coupons using scanning electron microscopy. As such, coupons with 192 hours of exposure were immersed for 15 minutes in solutions with increasing concentrations of ethanol up to $100 \%(\mathrm{vol} / \mathrm{vol})$, and placed in a sealed desiccator. The coupons were mounted on aluminium stubs with carbon tape, sputter coated with gold and observed with a Leica Cambridge S-360 SEM (Leo, Cambridge, UK).

\section{Results and discussion}

For the coupons removed from the pipe samples, and due to the technical problems encountered when adapting the PNA FISH method, it was readily concluded that we would be unable to assertively detect any $H$. pylori cells. One of the main problems was found to be the curvature of the pipes, as pipes with small diameters have large curvatures that hamper the task of focusing in the right plane. Adding to the curvature, the material itself might be so irregular that focusing is nearly impossible. This was, for instance, the case with cement. Deposits formed on the surface of other materials, such as cast iron, were also hampering factors for $H$. pylori detection. These problems probably might be overcome by using an episcopic differential interference contrast (EDIC), which uses objectives with long working distances (Keevil, 2003). Deposits can also be scraped, filtered and observed on the filter membrane surface, although in this case the 3D information on biofilm stucture is lost (Lehtola et al., 2006). 
It was also observed that autofluorescence was emitted by the biological material and the support material of most samples. The intensity of this effect was largely dependent on the type of sample analysed. The autofluorescence of biofilm material could obviously be a drawback for the PNA FISH detection, because of an increase in the risk of $H$. pylori misidentification and the possibility of overlooking the fluorescent signal of the probe against a brighter background. Autofluorescence can occur because of the composition of the pipe material, autofluorescent microorganisms and chemical or biological deposits on the surface and has been also found in other studies (Azevedo et al., 2003b; Lehtola et al., 2006). Chemical/physical methods can be tried to minimise or even eliminate fluorescence (Baschong et al., 2001; Neumann and Gabel, 2002), but an ideal solution would also involve the utilisation of a confocal scanning laser microscope (Conchello and Lichtman, 2005) and filter block manufacturers to provide custom-designed equipment.

Owing to all the problems described above, a biofilm formation device, the flow cell reactor, was installed in a bypass of the DWDS. Installing biofilm-forming devices as a bypass or directly connected to a DWDS has been a commonly used strategy to allow a more efficient monitoring of biofilm formation in real systems (e.g. Hallam et al., 2001; Lehtola et al., 2004). In our case, the device had one flat wall, and the coupons inserted were of PVC to minimise problems associated with deposits and autofluorescence of the material. Nevertheless, autofluorescence from both microorganisms and stacks was still observed. Therefore, strategies to eliminate the risk of a misidentification were included. The first involved the observation of all filter sets available in the epifluorescence microscope: a cell was only considered to be $H$. pylori if it emitted fluorescence in the filters sensitive to the probe and if no signal was detected in the non-sensitive filters. Second, it was considered that an unequivocal detection would depend on finding individual cells directly attached to the surface exhibiting typical $H$. pylori morphology. These considerations implied that cells embedded in stacks or fronds, where individual cells are not easily distinguished, were not considered to be H. pylori even if the fluorescence emission in the different filter sets was similar to the one provided by the probe. Finally, a negative control was performed to confirm the results obtained.

H. pylori has been sporadically detected directly adhered to the surface in nearly all of the coupons that have been used to perform the hybridisation experiment (Figure 2).
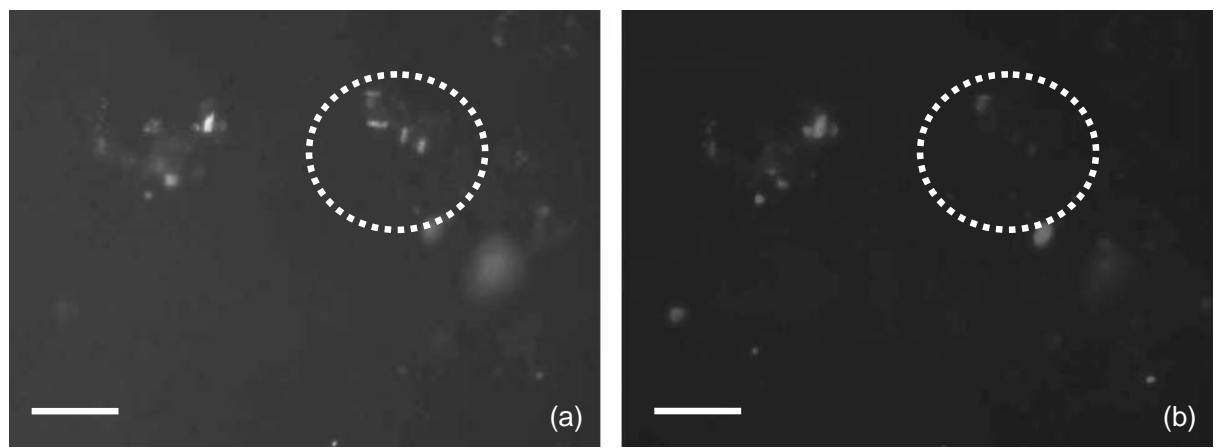

Figure 2 Episcopic fluorescence images of a mature biofilm formed in a PVC coupon that has been exposed to drinking water for 72 days. After hybridisation of the coupon with the specific PNA probe, H. pylori cells could be identified. Inside the white circles, three spiral/rod-like H. pylori cells are detected by the live/dead filter sensitive to the probe (a). In the same area, the Cy3 filter not sensitive to the probe is not able to pick those same cells (b). Outside the circle, autofluorescent biofilm structures and chemical deposits can also be detected, hampering the reliable detection of $H$. pylori in those particular areas. 
Notably, all morphological forms of the pathogen (spiral, rod and coccal) could be observed. In the control coupons, however, it was not possible to detect any H. pyloripositive sample demonstrating that the method provides sensitive and meaningful results. In all samples the number of $H$. pylori detected never exceeded 500 cells per $\mathrm{cm}^{2}$; however, this is likely to be a conservative number as many possible cells might not have been considered due to autofluorescence.

The detection of $H$. pylori, a pathogen with a very low survival time in water (Azevedo et al., 2004), in a chlorine disinfected DWDS might be surprising at first sight, but a possible explanation is given in a study by Baker and Hegarty (2002). When analysing the effect of oxidising disinfectants on $H$. pylori, they concluded that the pathogen would be more resistant than Escherichia coli to chlorine. Furthermore, the existence of eukaryotic microorganisms in these systems, such as Acanthamoeba castellanii, has been shown to promote the survival of the pathogen (Winiecka-Krusnell et al., 2002). Even though several different types of eukaryotic microorganisms have been consistently found in samples after more than 25 days, only a small proportion exhibited a similar morphology to the microorganisms of interest. Eukaryotes detected appeared to be mostly diatoms (single celled photosynthesising algae).

Besides this work, only one other group was capable of detecting H. pylori in noninoculated water samples using FISH technology (Moreno et al., 2003; Piqueres et al., 2006). Because sampling was performed in river and wastewater samples, one of the possible reasons this screening might have been successful was the lower amount of autofluorescence-emitting substances when compared to biofilm samples. This study, together with other studies using the PCR technique (Park et al., 2001; Krumbiegel et al., 2004; Rolle-Kampczyk et al., 2004; Watson et al., 2004), appear to indicate that the bacterium can indeed be commonly found in real water systems. As the preferred conditions for H. pylori attachment to abiotic surfaces have recently been described (Azevedo et al., 2006), the search of the bacterium in DWDS might now be performed under a more rational basis.

\section{Conclusions}

This work reports the in situ detection of $H$. pylori in biofilms formed in DWDS. The success of this detection is mainly due to two different factors: the installation of flow cells in a DWDS and the application of PNA probes instead of the standard DNA probes. Further improvement of the method is however needed before being routinely used in standard water analysis laboratories. Future work will involve coupling PNA FISH with viability dyes that will give an indication of the pathogen physiology in these systems. Nevertheless, spiral cells that are usually associated with the active form of the bacteria have been found, leading to renewed concerns about the possible transmission of H. pylori through the water.

\section{Acknowledgements}

We would like to thank Sandra Wilks, Talis Juhna and Markku Lehtola for their advice and helpful discussions on PNA FISH. This work was supported by the Portuguese Institute Fundação para a Ciência e Tecnologia (Grant SFRH/BPD/20484/2004) and by the European Commission Research Project SAFER (Contract $n^{\circ}$ EVK1-CT-2002-00108). Disclaimer: Authors are solely responsible for the work and the work presented does not represent the opinion of the Community and the Community is not responsible for the use that might be made of the data appearing therein. 


\section{References}

Axon, A. (2006). Helicobacter pylori: what do we still need to know? J. Clin. Gastroenterol., 40, 15-19. Azevedo, N.F., Pacheco, A.P., Vieira, M.J. and Keevil, C.W. (2004). Nutrient shock and incubation atmosphere influence recovery of culturable Helicobacter pylori from water. Appl. Environ. Microbiol., 70, 490-493.

Azevedo, N.F., Pinto, A.R., Reis, N.M., Vieira, M.J. and Keevil, C.W. (2006). Shear stress, temperature, and inoculation concentration influence the adhesion of water-stressed Helicobacter pylori to stainless steel 304 and polypropylene. Appl. Environ. Microbiol,, 72, 2936-2941.

Azevedo, N.F., Vieira, M.J. and Keevil, C.W. (2003a). Development of peptide nucleic acid probes to detect Helicobacter pylori in diverse species potable water biofilms. In Biofilm Communities: Order From Chaos? McBain, A., Allison, D., Brading, M., Rickard, A., Verran, J. and Walker, J. (eds), BioLine, Cardiff, pp. 105-112.

Azevedo, N.F., Vieira, M.J. and Keevil, C.W. (2003b). Establishment of a continuous model system to study Helicobacter pylori survival in potable water biofilms. Wat. Sci. Tech., 47, 155-160.

Baschong, W., Suetterlin, R. and Laeng, R.H. (2001). Control of autofluorescence of archival formaldehydefixed, paraffin-embedded tissue in confocal laser scanning microscopy (CLSM). J. Histochem. Cytochem., 49, $1565-1571$.

Baudart, J., Olaizola, A., Coallier, J., Gauthier, V. and Laurent, P. (2005). Assessment of a new technique combining a viability test, whole-cell hybridization and laser-scanning cytometry for the direct counting of viable Enterobacteriaceae cells in drinking water. FEMS Microbiol. Lett., 243, 405-409.

Bellack, N.R., Koehoorn, M.W., Macnab, Y.C. and Morshed, M.G. (2006). A conceptual model of water's role as a reservoir in Helicobacter pylori transmission: a review of the evidence. Epidemiol. Infec., 134, 439-449.

Benson, J.A., Fode-Vaughan, K.A. and Collins, M.L.P. (2004). Detection of Helicobacter pylori in water by direct PCR. Lett. Appl. Microbiol., 39, 221-225.

Blaser, M.J. and Atherton, J.C. (2004). Helicobacter pylori persistence: biology and disease. J. Clin. Invest., 113, 321-333.

Bunn, J.E.G., MacKay, W.G., Thomas, J.E., Reid, D.C. and Weaver, L.T. (2002). Detection of Helicobacter pylori DNA in drinking water biofilms: implications for transmission in early life. Lett. Appl. Microbiol., 34, 450-454.

Conchello, J.A. and Lichtman, J.W. (2005). Optical sectioning microscopy. Nat. Meth., 2, 920-931.

Flanigan, D. and Rodgers, M. (2003). A method to detect viable Helicobacter pylori bacteria in groundwater. Acta Hydroch. Hydrob., 31, 45-48.

Hallam, N.B., West, J.R., Forster, C.F. and Simms, J. (2001). The potential for biofilm growth in water distribution systems. Wat. Res., 35, 4063-4071.

Keevil, C.W. (2003). Rapid detection of biofilms and adherent pathogens using scanning confocal laser microscopy and episcopic differential interference contrast microscopy. Wat. Sci. Tech., 47, 105-116.

Krumbiegel, P., Lehmann, I., Alfreider, A., Fritz, G.J., Boeckler, D., Rolle-Kampczyk, U., Richter, M., Jorks, S., Muller, L., Richter, M.W. and Herbarth, O. (2004). Helicobacter pylori determination in nonmunicipal drinking water and epidemiological findings. Isot. Environ. Health S., 40, 75-80.

Lehtola, M.J., Juhna, T., Miettinen, I.T., Vartiainen, T. and Martikainen, P.J. (2004). Formation of biofilms in drinking water distribution networks, a case study in two cities in Finland and Latvia. J. Ind. Microbiol. Biol., 31, 489-494.

Lehtola, M.J., Loades, C.J. and Keevil, C.W. (2005). Advantages of peptide nucleic acid oligonucleotides for sensitive site directed 16S rRNA fluorescence in situ hybridization (FISH) detection of Campylobacter jejuni, Campylobacter coli and Campylobacter lari. J. Microbiol. Meth., 62, 211-219.

Lehtola, M.J., Torvinen, E., Miettinen, L.T. and Keevil, C.W. (2006). Fluorescence in situ hybridization using peptide nucleic acid probes for rapid detection of Mycobacterium avium subsp avium and Mycobacterium avium subsp paratuberculosis in potable-water biofilms. Appl. Environ. Microbiol., 72, $848-853$.

Lu, Y.Z., Redlinger, T.E., Avitia, R., Galindo, A. and Goodman, K. (2002). Isolation and genotyping of Helicobacter pylori from untreated municipal wastewater. Appl. Environ. Microbiol., 68, 1436-1439.

Moreno, Y., Ferrus, M.A., Alonso, J.L., Jimenez, A. and Hernandez, J. (2003). Use of fluorescent in situ hybridization to evidence the presence of Helicobacter pylori in water. Wat. Res., 37, 2251-2256.

Neumann, M. and Gabel, D. (2002). Simple method for reduction of autofluorescence in fluorescence microscopy. J. Histochem. Cytochem., 50, 437-439. 
Nielsen, P.E., Egholm, M., Berg, R.H. and Buchardt, O. (1991). Sequence-selective recognition of DNA by strand displacement with a thymine-substituted polyamide. Science, 254, 1497-1500.

Park, S.R., Mackay, W.G. and Reid, D.C. (2001). Helicobacter sp. recovered from drinking water biofilm sampled from a water distribution system. Wat. Res., 35, 1624-1626.

Piqueres, P., Moreno, Y., Alonso, J.L. and Ferrus, M.A. (2006). A combination of direct viable count and fluorescent in situ hybridization for estimating Helicobacter pylori cell viability. Res. Microbiol., 157, 345-349.

Prescott, A.M. and Fricker, C.R. (1999). Use of PNA oligonucleotides for the in situ detection of Escherichia coli in water. Mol. Cell. Probes, 13, 261-268.

Rolle-Kampczyk, U.E., Fritz, G.J., Diez, U., Lehmann, I., Richter, M. and Herbarth, O. (2004). Well water one source of Helicobacter pylori colonization. Int. J. Hyg. Environ. Health, 207, 363-368.

Savichtcheva, O., Okayama, N., Ito, T. and Okabe, S. (2005). Application of a direct fluorescence-based live/ dead staining combined with fluorescence in situ hybridization for assessment of survival rate of Bacteroides spp. in drinking water. Biotechnol. Bioeng., 92, 356-363.

Stender, H., Fiandaca, M., Hyldig-Nielsen, J.J. and Coull, J. (2002). PNA for rapid microbiology. J. Microbiol. Methods, 48, 1-17.

Watson, C.L., Owen, R.J., Said, B., Lai, S., Lee, J.V., Surman-Lee, S. and Nichols, G. (2004). Detection of Helicobacter pylori by PCR but not culture in water and biofilm samples from drinking water distribution systems in England. J. Appl. Microbiol., 97, 690-698.

Winiecka-Krusnell, J., Wreiber, K., Von Euler, A., Engstrand, L. and Linder, E. (2002). Free-living amoebae promote growth and survival of Helicobacter pylori. Scand. J. Infect. Dis., 34, 253-256. 